\title{
AS REPRESENTAÇÕES SOCIAIS DO TRABALHO INFANTIL PARA FAMÍLIAS COM HISTÓRICO DE TRABALHO
}

\author{
Aline Madia Mantovani \\ Universidade Estadual Paulista - FCT/UNESP. Presidente Prudente/SP. E-mail: alinemadia@hotmail.com - \\ Financiamento: CAPES.
}

\section{RESUMO}

O presente estudo faz uma análise das representações sociais do trabalho infantil construídas e compartilhadas por quatro famílias com histórico de trabalho desde a infância e adolescência. 0 enfoque dado à discussão busca articular os aspectos positivos e negativos do trabalho infantil e a subjetividade de sujeitos trabalhadores, dada a multiplicidade de sentidos atribuídos ao fenômeno. Os dados foram obtidos através de entrevistas semiestruturadas junto a quatro famílias oriundas de duas escolas públicas estaduais de Presidente Prudente/SP e apontam para a necessidade de ações e políticas públicas voltadas mais para o sujeito trabalhador e menos para discursos reducionistas do trabalho infantil. Torna-se necessário, assim, entender o trabalho infantil a partir do contexto histórico e da legislação vigente, articulando-o às representações sociais presentes no contexto de trabalhadores precoces.

Palavras-chave: Trabalho Infantil. Representações sociais. Família. Aspectos positivos e negativos. Contexto histórico.

\section{SOCIAL REPRESENTATIONS OF CHILD LABOUR FOR FAMILIES WITH WORK HISTORY}

\begin{abstract}
This study is an analysis of the social representations of child labor built and shared by four families with a history of work from childhood and adolescence. The focus given to the discussion seeks to articulate the positive and negative aspects of child labor and the subjectivity of workers subject, given the multiplicity of meanings attributed to the phenomenon. Data were collected through semi-structured interviews with four families from two public schools in Presidente Prudente/SP and point to the need for action and public policies more to the employee and subject to less reductionist discourses of child labor. It becomes necessary therefore to understand child labor from the historical context and current legislation, linking it to social representations present in the context of early workers.

Keywords: Child Labor. Social representations. Family. Positive and negative aspects. Historical context.
\end{abstract}




\section{INTRODUÇÃO}

Há alguns anos atrás era comum encontrarmos crianças e adolescentes em fábricas, nas ruas e nas fazendas, com seus pais ou pessoas desconhecidas, prestando serviços a preços bem abaixo daqueles pagos aos adultos.

Para Nunes (2009) a utilização da mão de obra infantil já ocorria dois mil anos antes de Cristo, pois os menores eram submetidos ao regime geral e deviam trabalhar arduamente desde que tivessem relativo desenvolvimento físico.

A situação de trabalho infanto-juvenil se agravou com o advento da Revolução Industrial iniciada na Inglaterra no século XVIII. No Brasil, Cosendey (2002) faz referência à participação de crianças indígenas em situações laborativas desde o início da nossa colonização e Kassouf (2005) pontua o trabalho realizado pelos filhos de escravos, que consistia em acompanhar os pais nas mais diversas atividades e exercer tarefas que exigiam esforços muito superiores as suas possibilidades físicas.

Diante deste panorama, podemos notar que o trabalho infantil não é um fenômeno recente na história da humanidade e que é a partir do reconhecimento de suas potenciais consequências negativas que surgiram as normativas legais com vistas a sua definição e eliminação.

Na Constituição Federal de 1988 (BRASIL, 1990) e no Estatuto da Criança e do Adolescente (ECA, 1990) entende-se como "infantil" o trabalho exercido por qualquer pessoa antes dos 14 anos de idade, salvo na condição de aprendiz.

Em âmbito internacional, contamos com os princípios prescritos pela Organização Internacional do Trabalho (OIT) nas Convenções no 138 (referente à idade mínima para admissão no emprego) e $\mathrm{n}-182$ (que define as piores formas de trabalho infantil), ambas ratificadas pelo Brasil.

Sendo assim, estamos entendendo como "infantil" o trabalho exercido por qualquer pessoa antes da idade mínima permitida por lei, nas modalidades "doméstico", "informal urbano" e "rural".

O trabalho infantil doméstico configura-se como os afazeres domésticos de cuidar de casas, pessoas ou animais, executados para a própria família ou para terceiros, podendo envolver ou não alguma forma de pagamento (ALBERTO et. al., 2005).

Já o trabalho infantil informal urbano refere-se ao envolvimento de crianças e adolescentes em atividades fora do mercado formal e sem regulamentação, que se dá nas áreas urbanas, 
enquanto o trabalho infantil rural configura-se como categoria de trabalho que emprega menores na agricultura (STROPASOLAS, 2012).

Este envolvimento histórico de crianças e adolescentes em situações de trabalho, remuneradas ou não, tem sido considerado de diferentes formas, ora revestido de aspectos negativos ao desenvolvimento, ora considerado fator positivo para quem o exerce. Á primeira vista contraditórias, tais definições alertam para a multiplicidade de sentidos que envolvem o trabalho infantil e a fragilidade que tem uma visão linear sobre o fenômeno.

Sendo assim, configura-se como objetivo do presente estudo compreender as representações sociais do trabalho infantil construídas e compartilhadas por quatro famílias advindas de duas escolas públicas estaduais de Presidente Prudente/SP, com vistas a problematiza-lo a partir de temas como os aspectos da saúde do trabalhador, trabalho infantil e pobreza/renda, trabalho infantil e escolarização e subjetividade da criança trabalhadora.

\section{METODOLOGIA}

Os dados apresentados neste estudo fazem parte da pesquisa desenvolvida por Mantovani (2012), cuja temática centra-se nas representações sociais de famílias e profissionais da educação sobre o trabalho infantil, com enfoque sobre o desenvolvimento e a escolarização. Estamos considerando aqui os dados obtidos na Fase II do estudo, qual seja, as entrevistas semiestruturadas com quatro famílias.

Esses participantes caracterizavam-se por serem "homem" e "mulher" e "não aprovarem" o trabalho infantil (aspectos negativos) e "homem" e "mulher" e o "aprovarem" (aspectos positivos).

Todos eles participaram de uma entrevista semiestruturada e receberam orientações para que registrassem com uma máquina fotográfica situações, pessoas e/ou lugares que os remetessem as representações sociais que construíram acerca do trabalho infantil.

A utilização da fotografia se deu por partilharmos com Harper (2002) que o uso de métodos visuais - fotografia e filmagem - em pesquisas qualitativas possibilita a construção de novas formas de conhecimento que, muitas vezes, não teriam sido possíveis através de outros instrumentos, como entrevistas e questionários, por exemplo.

Após a devolução das máquinas realizamos uma entrevista sobre as imagens obtidas com o objetivo de compreender as fotografias registradas e alguns pontos do questionário e da primeira entrevista que não haviam ficado claros. 
Faz-se necessário destacarmos que essa pesquisa atende aos aspectos éticos da pesquisa com seres humanos e seu projeto foi encaminhado ao Comitê de Ética em Pesquisa da FCT/UNESP de Presidente Prudente, recebendo parecer favorável a sua execução (Protocolo de Pesquisa no 86/2009).

\section{RESULTADOS}

Para facilitar a compreensão do leitor vamos, inicialmente, caracterizar as quatro famílias participantes, ressaltando sua identidade foi mantida em sigilo. As duas mulheres serão denominadas, respectivamente, por "M1" - mulher que não aprova o trabalho infantil - e "M2" mulher que o aprova. Quanto aos homens, serão, respectivamente, "H1" - homem que não aprova o trabalho infantil - e "H2" - homem que o aprova.

Todos os participantes são casados, tem filhos e moram em residências próprias, advindos de famílias numerosas, marcadas pela pobreza e escassez de recursos alimentícios, de vestuário e de higiene. Atualmente, M1 é recepcionista em um hospital; M2 é cozinheira em uma escola pública; H1 é caseiro em uma fazenda e H2 é o pizzaiolo de sua própria pizzaria.

\section{DISCUSSÃO}

Para aqueles que não aprovam o trabalho infantil, a infância foi marcada pelo exercício do trabalho doméstico (M1) junto à mãe e pelo trabalho em olaria e chácaras (H1), sem momentos de diversão e brincadeira, importantes para o desenvolvimento do ser humano. Para M1 este período resultou em implicações sobre sua saúde e H1 relata que acordava muito cedo, juntamente com os pais e os irmãos, para irem para a olaria, que ficava próxima a casa deles. Lá trabalhava o dia todo, sem muito tempo para brincar e ir à escola.

A infância de $M 2$ também foi marcada pelo trabalho doméstico em sua própria casa. No entanto, a participante relata que o trabalho era dividido entre seus irmãos e ocorria em horário contrário ao período escolar; ela também relata que brincava muito com seus irmãos e vizinhos em rios e na rua.

Para H2 o trabalho também se iniciou durante a infância, em lojas e como office boy em um banco, para que fosse possível "dar suporte aos irmãos menores para que começassem a trabalhar mais tarde". O participante fala sobre sua participação em atividades de lazer e a prática de esportes que ajudavam em seu desenvolvimento.

Quanto à escolarização, M1teve que parar os estudos aos 12 anos e só terminar o Ensino Médio após dar à luz as suas três filhas. H1 parou de estudar na 4a série, pois morava longe da 
escola e acordava muito cedo para ir à olaria com o pai; M2 terminou o Ensino Médio e contava com o apoio e incentivo da mãe para estudar, revezando as tarefas domésticas com os irmãos. H2 relata que foi o único entre seus irmãos a começar a trabalhar cedo e a concluir o Ensino Médio.

Podemos observar que o fato de aprovar ou não o trabalho infantil vem de uma concepção construída a partir de sua própria experiência de trabalho durante a infância e adolescência e associa-se a fatores como a intensidade do trabalho realizado, o apoio ou não de familiares, o(s) motivo(s) da inserção no trabalho, o grau de pobreza da família e os prejuízos ao processo de escolarização e outras esferas da vida.

Os aspectos negativos e positivos do trabalho infantil foram destacados por essas famílias durante toda a pesquisa, nos levando a considerar em suas falas a multiplicidade de sentidos do trabalho infantil e a necessidade de olharmos para este fenômeno de forma mais centrada sobre a subjetividade de quem o exerce.

O caráter negativo do trabalho infantil, observado acentuadamente na fala de $\mathrm{M} 1$ e $\mathrm{H} 1$, é considerado uma violação dos direitos fundamentais garantidos por lei por acarretar prejuízos físicos, psicológicos e escolares bastante preocupantes, conforme prescrições de alguns autores e organizações (BLAGBROUGH, 2008; KASSOUF, 2005; MOREIRA E STENGEL, 2003; ORGANIZAÇÃO INTERNACIONAL DO TRABALHO/OIT).

No entanto, apesar destes aspectos negativos, também foi possível encontramos participantes que o consideram de forma positiva, como $\mathrm{M} 2$ e $\mathrm{H} 2$, corroborando os estudos de alguns autores e organismos multilaterais, como Alves-Mazzotti (2002), Invernizzi (2003), Liebel (2003), Sarmento (2005) e Woodhead (1999). Tais autores baseiam-se em uma postura que considera a forma como o próprio sujeito trabalhador avalia a sua prática e apontam para uma visão mais flexível, discutindo a possibilidade de o trabalho infantil ser, em algumas situações, fator positivo.

Partindo da subjetividade e do ponto de vista dos participantes pudemos perceber quais fatores contribuíram para a construção de representações negativas do trabalho infantil, bem como percebemos que foi a partir do trabalho que tiveram a oportunidade de se desenvolverem satisfatoriamente. As imagens registradas pelos participantes e as explicações que deram sobre elas nos ajudaram a construir tais concepções.

Para M1, que não aprova o trabalho infantil, as imagens se voltaram para sua casa e a casa de seus pais, reforçando a ausência da mãe em sua vida e a casa em que moram como "simples", pelo fato de serem pobres e não terem condições de algo melhor pela falta de estudos. H1 
registrou a olaria em que trabalhou com a família relatando, inclusive, os problemas de saúde que os irmãos e tio tiveram no manuseio daquelas máquinas.

Aos que aprovam o trabalho infantil, as imagens nos remetiam à ideia de que as crianças podem desenvolver algumas atividades como lavar a louça, capinar com o pai e vender sorvetes (opinião de M2) e também que algumas atividades são consideradas informais (ciganos que leem a mão no centro da cidade), perigosas e de alto risco (em supermercado sem equipamentos de segurança e no transporte de dinheiro) (H2), elementos que, talvez, não seriam levantados se não observássemos a subjetividade do próprio trabalhador e contássemos com o uso de máquinas fotográficas.

\section{ALGUMAS CONSIDERAÇÕES}

O trabalho infantil é um fenômeno histórico, social e cultural que passa a ser investigado recentemente devido aos prejuízos que acarreta sobre a saúde física, psíquica e emocional de quem o exerce. Também é por esta preocupação que organismos nacionais e internacionais se dedicam à elaboração de leis, decretos e convenções que o proíbe.

No entanto, em nosso estudo buscamos problematizar discursos generalistas sobre o trabalho infantil, principalmente cercados por uma definição negativa do fenômeno, para tentar compreender as representações sociais de sujeitos que trabalharam durante sua infância e/ou adolescência, tanto em atividades domésticas, como em informais urbanas e rurais, dando a esse entendimento um olhar mais subjetivo.

Diante desse panorama percebemos a multiplicidade de sentidos do trabalho infantil, fenômeno caracterizado ora por fatores negativos ao desenvolvimento e à escolarização, ora concebido como algo positivo.

Lembramos que não estamos defendendo o trabalho infantil, mas alertando para o fato de que não podemos considera-lo por um único viés de interpretação, que principalmente defende sua total eliminação, mas que é possível, em algumas situações e quando consideramos a subjetividade do trabalhador, defini-lo como algo positivo.

\section{REFERÊNCIAS}

ALBERTO, M. F. P. et. al. O trabalho infantil doméstico em João Pessoa/PB: um diagnóstico rápido à luz das piores formas de trabalho infantil. João Pessoa: OIT, 2005.

ALVES-MAZZOTTI, A. J. Repensando algumas questões sobre o trabalho infanto-juvenil. Revista Brasileira de Educação, n. 19, 2002, p. 87-98. 
BLAGBRough, J. Child Domestic Labour: a modern form of slavery. Canada: Children and Society, n. 22, p. 179-190, 2008. http://dx.doi.org/10.1111/j.1099-0860.2008.00149.x

BRASIL. Constituição da República Federativa do Brasil: promulgada em 05 de outubro de 1988. 4. ed. São Paulo: Saraiva, 1990. 168 p.

COSENDEY, E. M. V. M. O trabalho infanto-juvenil: características e malefícios. In: MARQUES, M. E., NEVES, M. A.; NETO, A. C. (Org.). Trabalho Infantil: a infância roubada. Belo Horizonte: Editora da Pontifícia Universidade Católica de Minas Gerais, 2002.

HARPER, D. Talking about pictures: a case for photo elicitation. Visual Studies, v.17, n. 1, 2002. http://dx.doi.org/10.1080/14725860220137345

INVERNIZZI, A. Street working children and adolescents in Lima: work as an agent of socialization. Childhood, v. 10, n. 3, 2003, p. 319-341. http://dx.doi.org/10.1177/09075682030103005

KASSOUF, A. L. A ameaça e o perigo à saúde impostos às crianças e aos jovens em determinados trabalhos. In: CORRÊA, L. B.; VIDOTTI, T. J. (coord.). Trabalho infantil e direitos humanos. São Paulo: LTr, 2005, p. 121-145.

LIEBEL, M. Working children as social subjects: the contribution of working children's organizations to social transformations. Childhood, n.10, 2003, p. 265-285.

MANTOVANI, A. M. Trabalho Infantil e desenvolvimento na perspectiva de profissionais da educação e famílias. 2012. 155f. Dissertação (Mestrado em Educação) - Faculdade de Ciências e Tecnologia, Universidade Estadual Paulista, Presidente Prudente.

MOREIRA, M. I. C.; STENGEL, M. (Orgs.). Narrativas infanto-juvenis sobre trabalho doméstico. Belo Horizonte: Editora da PUC Minas, Save the Children, 2003.

NUNES, I. B. O Trabalho Infantil na Revolução Industrial Inglesa: uma contribuição ao trabalho docente na sétima série, 2009.

ORGANIZAÇÃO INTERNACIONAL DO TRABALHO. Convenção no 138. Convenção sobre a Idade Mínima para Admissão. Disponível em http://www.oit.org.br, acesso em junho de 2014.

. Convenção no 182 . Convenção sobre as

piores formas de trabalho infantil. Disponível em http://www.oit.org.br, acesso em junho de 2014.

SARMENTO, M. J. Trabalho Infantil em Portugal: Controvérsias e Realidades. In: VIEIRA, C. et al. Ensaios sobre o Comportamento Humano. Coimbra: Almedina, p. 95-116, 2005.

STROPASOLAS, V. L. Trabalho Infantil no campo: do problema social ao objeto sociológico. Revista Latino-Americana de Estudos do Trabalho, ano 17, no 27, 2012, p. 249-286.

WOODHEAD, M. Combating child labor - Listen to what children say. Childhood, v.6, 1999, p.2749. http://dx.doi.org/10.1177/0907568299006001003 